\title{
Thermal-stress resistance and fracture toughness of two tool ceramics
}

\author{
Y.W. MAl* \\ Department of Mechanical Engineering, University of Michigan, Ann Arbor, \\ Michigan, USA
}

The thermal-stress resistance and fracture strength behaviour of two oxide ceramics (a hot-pressed pure $\mathrm{Al}_{2} \mathrm{O}_{3}$ and a composite ceramic NTK-HC2) subjected to severe thermal shocks have been investigated. The damage resistance parameter $\left(K_{\mathrm{IC}} / \sigma_{\mathrm{f}}\right)^{2}$ for both ceramics is also determined for a wide range of temperatures $\left(25^{\circ}\right.$ to $\left.800^{\circ} \mathrm{C}\right)$ and cross-head rates $\left(10^{-2} \mathrm{~cm} \mathrm{~min}^{-1} \sim 2.5 \mathrm{~m} \mathrm{sec}^{-1}\right)$. Fracture strength behaviour of these two oxide ceramics is shown to follow Hasselman's model where the instantaneous strength loss at the critical quenching temperature may be calculated using appropriate $\left(K_{\mathrm{IC}} / \sigma_{\mathrm{f}}\right)^{2}$ values to give good agreement with experimental results. Repeated shocks show some further degradation in the retained strength for both ceramics so that these materials are susceptible to thermal fatigue. It is found that both materials possess similar resistance to crack initiation (i.e. similar $\Delta T_{\mathrm{c}}$ and retained strength after shocking through $\left.\Delta T_{\mathrm{c}}\right)$ but the pure oxide ceramic has higher resistance to crack propagation.

\section{Introduction}

Although thermal shock induced fractures in both carbide and ceramic tools during cutting operations are not uncommon, they have, however, received relatively little attention in the past. Recent work [1-3] has shown that the effects of thermal shock on the fracture strength behaviour of some typical tool carbides (e.g. tungsten carbide and titanium carbide) can be described by the Hasselman model [4], so that at their respective critical temperatures, strength discontinuities are observed in the retained strength versus quenching temperature plots. Two thermal stress resistance parameters have been introduced $[1,4]$ to characterize the resistances to crack initiation and crack propagation. These are, respectively, $\left(k \sigma_{\mathrm{f}} / E \alpha\right)$ and $\left(K_{\mathrm{IC}} / \sigma_{\mathrm{f}}\right)^{2}$, where $k$ is the thermal conductivity; $\sigma_{\mathrm{f}}$, transverse rupture strength; $E$, Young's modulus; $\alpha$, linear coefficient of thermal expansion; and, $K_{\text {IC }}$, the fracture toughness.

In the present investigation, which is a continuation of previous work reported in $[1-3]$, the fracture strength behaviour and thermal stress resistance of two "candidate" oxide ceramic tools used in high speed cutting operations are studied and compared. Since the damage resistance parameter $\left(K_{\text {IC }} / \sigma_{\mathrm{f}}\right)^{2}$, which is useful for correlating crack propagation resistance and strength loss after the critical shocking temperature, may be both temperature and rate dependent $[1,4]$, the effects of temperature $\left(25\right.$ to $\left.800^{\circ} \mathrm{C}\right)$ and loading rate $\left(10^{-2} \mathrm{~cm} \mathrm{~min}^{-1}\right.$ to $\left.2.5 \mathrm{~m} \mathrm{sec}^{-1}\right)$ on the fracture toughness $\left(K_{\mathrm{IC}}\right)$ and transverse rupture strength $\left(\sigma_{f}\right)$ are, therefore, separately determined. Residual strength experiments after thermal shocks at various temperatures are also conducted for these two oxide ceramics and their residual strength behaviour analysed using the previously determined $\left(K_{\text {IC }} / \sigma_{f}\right)^{2}$ parameters.

\section{Materials}

The two oxide ceramics chosen for the present study are a pure hot-pressed alumina (with additives of oxides of titanium and magnesium)

\footnotetext{
* Present address: Department of Mechanical Engineering, Imperial College of Science and Technology, Iondon, UK.
} 


\begin{tabular}{|c|c|c|}
\hline Quantity & Hot-pressed $\mathrm{Al}_{2} \mathrm{O}_{3}$ & NTK-HC2 (composite ceramic) \\
\hline Density $\left(\mathrm{g} \mathrm{cm}^{-3}\right)$ & 3.98 & 4.30 \\
\hline Hardness (Rockwell A) & 9394 & 94.5 \\
\hline$\sigma_{\mathrm{f}}\left(10^{3} \mathrm{psi}\right)$ & $70 \sim 90$ & $\sim 100$ \\
\hline$E\left(\times 10^{6}\right)(\mathrm{psi})$ & $53 \sim 60$ & 45 \\
\hline$\nu$ & 0.25 & 0.25 \\
\hline$k\left(\mathrm{cal} \mathrm{sec}{ }^{-1}{ }^{\circ} \mathrm{C}^{-1} \mathrm{~cm}^{-1}\right)$ & 0.0675 & 0.05 \\
\hline$\alpha\left({ }^{0} \mathrm{C}^{-1}\right)$ & $7.6 \times 10^{-6}$ & $7.9 \times 10^{-6}$ \\
\hline$\beta$ (Biot modulus) & $3.76 \sim 4.70$ & $2.0 \sim 2.50$ \\
\hline
\end{tabular}

and a composite alumina* (with titanium carbide). Some typical physical and mechanical properties of these oxide ceramics are given in Table $\mathbf{I}$.

\section{Experimental procedures}

\subsection{Temperature-dependent strength measurements}

Three-point bend specimens of dimensions 0.25 in $\times 0.20$ in $\times 1.25(1.00)$ in. were prepared (by the respective manufacturers) and broken in an Instron testing machine at a cross-head rate of $0.10 \mathrm{~cm} \mathrm{~min}^{-1}$. The span was fixed at $1 \mathrm{in}$. Values of tensile strength were obtained at temperatures ranging from 25 to $800^{\circ} \mathrm{C}$.

\subsection{After-shock residual strength measurements}

Three-point bend specimens with sizes same as those described above were shocked through different temperatures within the range of 200 to $800^{\circ} \mathrm{C}$ by first heating in an electric furnace to the required temperature and then quenching in water at about $28^{\circ} \mathrm{C}$. The shocked specimens were then dried and broken at room temperature in three point bending, at a cross-head rate of $0.05 \mathrm{~cm}$ $\min ^{-1}$. Some experiments were also performed to investigate the effects of repeated shocks on the residual strength $\left(\sigma_{\mathrm{a}}\right)$ of the shocked ceramics.

\subsection{Toughness determination}

Fracture toughness values for both oxide ceramics were determined using bend specimens as those described in Sections 3.1 and 3.2. Elliptical surface cracks were introduced to the testpieces by surface indentation using a Knoop diamond indenter. This gave very consistent precrack sizes with 1.0 to $1.5 \mathrm{~mm}$ length $(2 a)$ and $\sim 0.8 \mathrm{~mm}$ depth $(b)$. The fracture toughness $\left(K_{\mathrm{IC}}\right)$ under three-point bend cracking was determined using the same equation as reported in [1] and [3] .

$$
\text { i.e. } \begin{aligned}
K_{\mathrm{IC}}= & \frac{3}{2} \frac{X L b^{1 / 2}}{B W^{2}}\left[1.96-2.75\left(\frac{b}{W}\right)\right. \\
& +13.66\left(\frac{b}{W}\right)^{2}-23.98\left(\frac{b}{W}\right)^{3} \\
& \left.+25.22\left(\frac{b}{W}\right)^{4}\right] \Phi^{-1}
\end{aligned}
$$

when $\Phi$ the elliptical integral is given by

$$
\Phi=\int_{0}^{\pi / 2}\left(1-\frac{a^{2}-b^{2}}{a^{2}} \sin ^{2} \theta\right)^{1 / 2} \mathrm{~d} \theta,
$$

where $X$ is the fracture load, $L$ the length of span, $B$ and $W$ are specimen thickness and depth respectively.

The fracture toughness of these ceramics was also obtained as a function of temperature (25 to $\left.800^{\circ} \mathrm{C}\right)$ and loading rate $\left(0.05\right.$ to $\left.50 \mathrm{~cm} \mathrm{~min}^{-1}\right)$.

\section{Results and discussion}

\subsection{Thermal shock, temperature and loading rate effects on transverse rupture strength $\left(\sigma_{f}\right)$}

Figs. 1 and 2 show the retained room temperature strength versus shocking temperature interval results for the pure hot-pressed alumina and the composite ceramic NTK-HC2 respectively. Obviously, both oxide ceramics follow the Hasselman model and show distinct strength discontinuities with considerable strength loss at their respective critical quenching temperatures $\left(T_{\mathbf{c}}\right)$. It has been shown $[5,6]$ that the critical temperature difference is given by

$$
\Delta T_{\mathrm{c}}=\left(T_{\mathrm{c}}-T_{\mathrm{w}}\right) \approx \frac{\sigma_{\mathrm{f}}(1-\nu)}{3 E \alpha \psi}
$$

and

$$
\psi^{-1}=1.50+\frac{3.25}{\beta}-0.5 \mathrm{e}^{-16 / \beta},
$$

\footnotetext{
* NTK cutting tools, NGK Spark Plug Co, Ltd, USA, Grade NTK-HC2.
} 
where $T_{\mathrm{w}}$ is the water bath temperature and $\beta$ is the Biot modulus $(=a h / k) . a$ is the half thickness of the test sample, $k$ the thermal conductivity and $h$ the heat transfer coefficient.

Assuming for a water quench, $h \approx 1 \mathrm{cgs}$ unit, $a h / k$ for the hot-pressed alumina and NTK-HC2 are roughly 3.16 and 2.00 respectively. Thus, using Equations 1 and 2 and with $\sigma_{\mathbf{f}}, E, \alpha$ values from Table I, the critical quenching temperature differences calculated are respectively 132 and $197^{\circ} \mathrm{C}$. These results are, therefore, in good agreement with corresponding experimental values of 172 and $175^{\circ} \mathrm{C}$ as shown in Figs. 1 and 2.
A necessary condition for the catastrophic cracking and hence the discontinuity in the retained strength behaviour according to the Hasselman theory is that initial cracks must not have effective crack lengths $\left(r_{0}\right)$ greater than approximately $1 \mathrm{~mm}[4]$. The effective crack lengths estimated from an expression derived for fracture in a penny-shaped crack by Sack [7] are $0.08 \mathrm{~mm}$ for the hot-pressed $\mathrm{Al}_{2} \mathrm{O}_{3}$ and $0.04 \mathrm{~mm}$ for the composite ceramic NTK-HC2. Clearly, these values are much smaller than the limiting value specified by Hasselman and thus explains the catastrophic spreading and arrest behaviour of

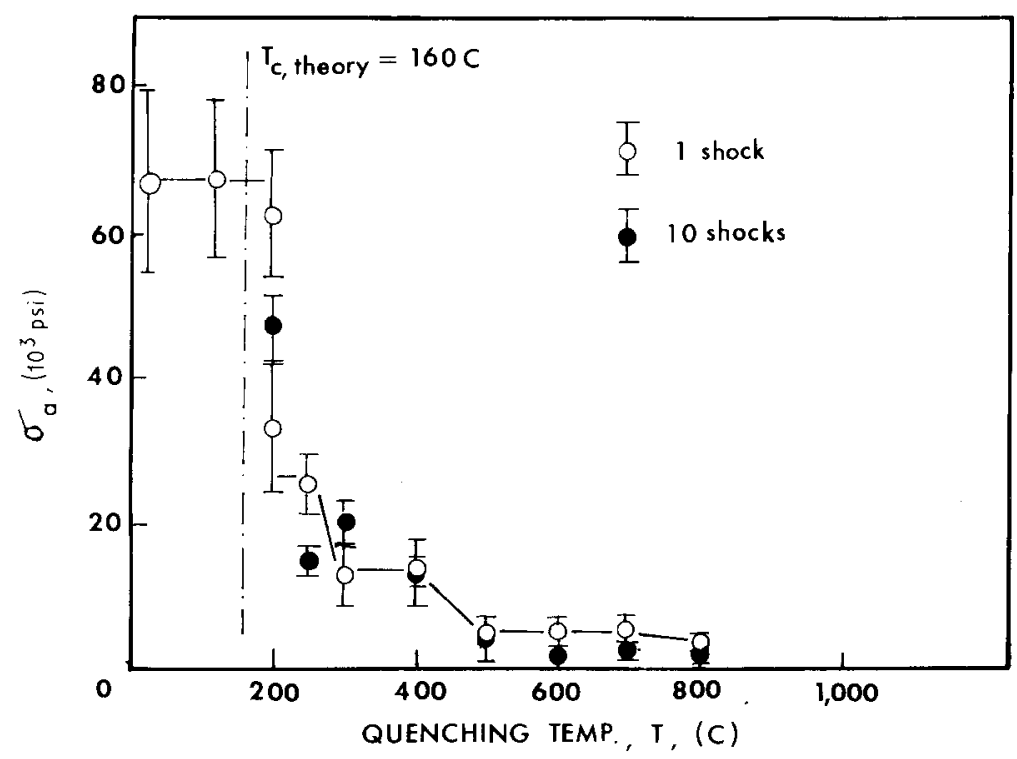

Figure 1 Fracture strength behaviour of hot-pressed alumina, showing retained strength $\left(\sigma_{\mathbf{a}}\right)$ versus quenching temperature (T).

Figure 2 Retained strength $\left(\sigma_{\mathrm{a}}\right)$ yersus quenching temperature $(T)$ for the composite ceramic NTK-HC2.

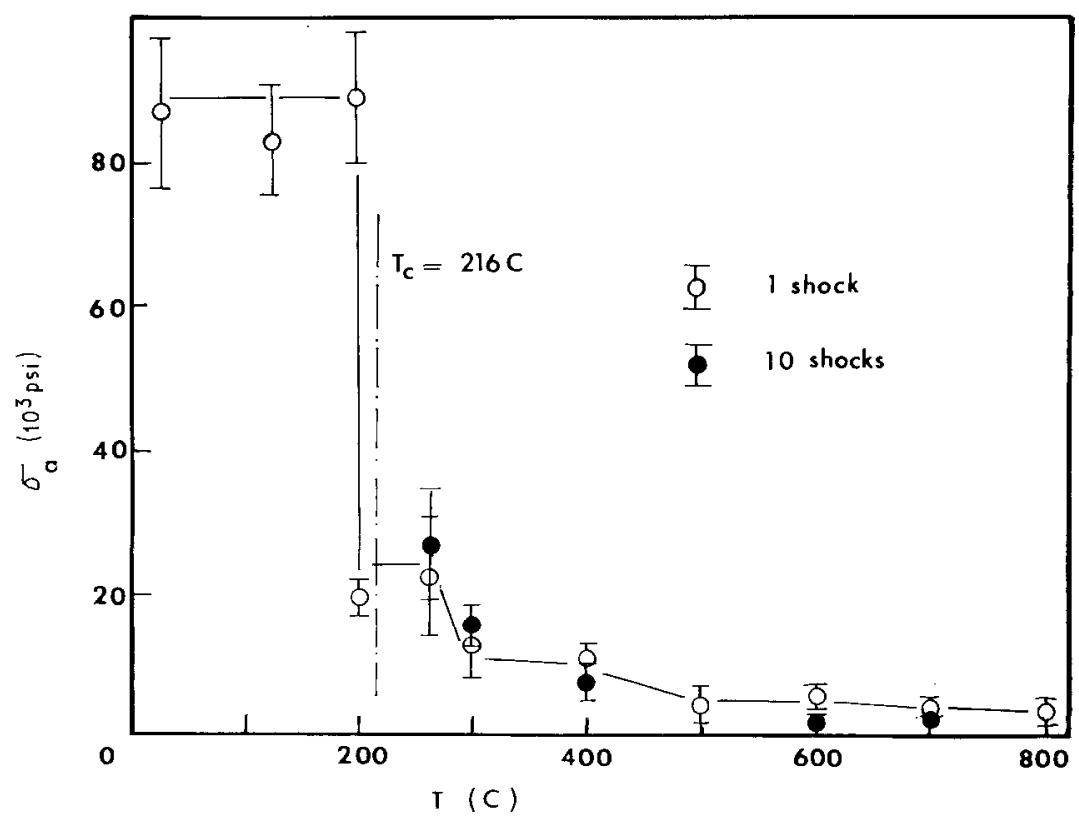




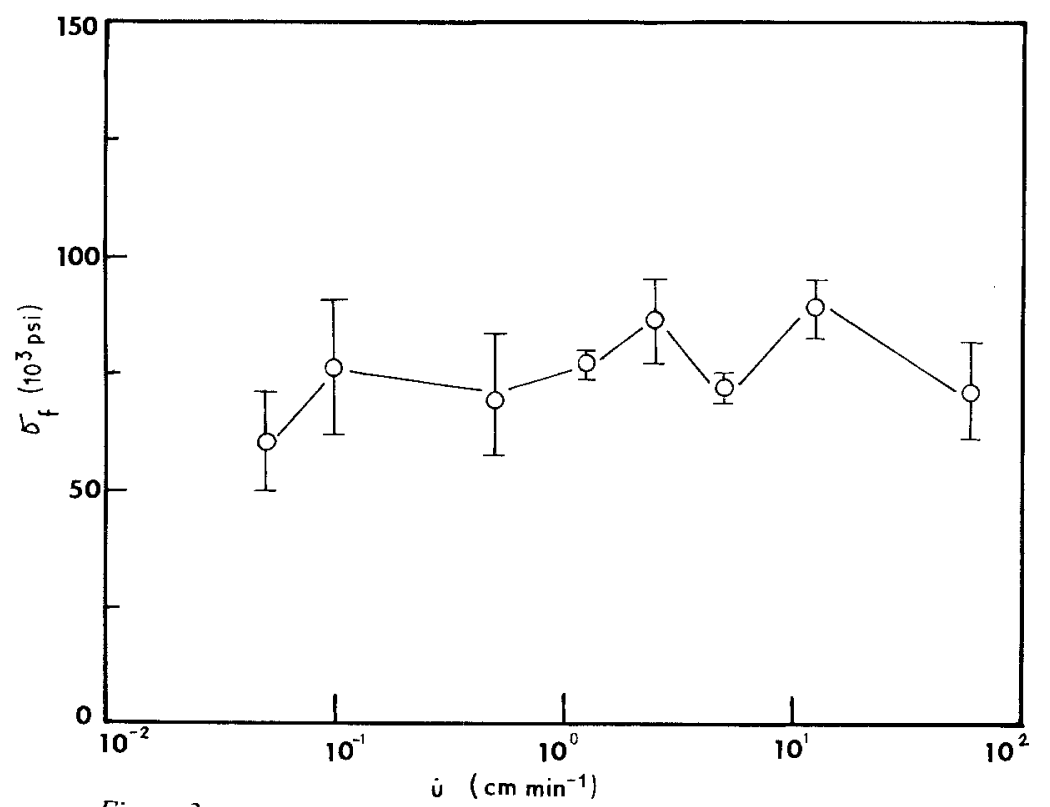

Figure 3.

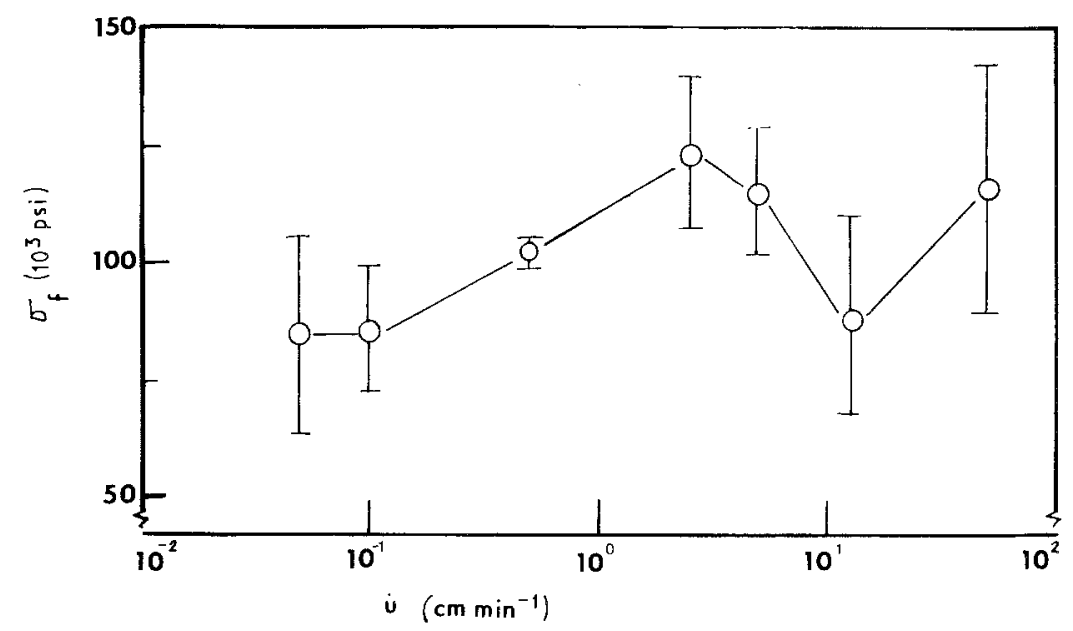

Figure 4.

Figures 3 and 4 Dependence of bend strength $\left(\sigma_{\mathrm{f}}\right)$ on cross-head rate $(\dot{u})$ for hot-pressed $\mathrm{Al}_{2} \mathrm{O}_{3}$ (Fig. 3) and NTK-IIC2 (Fig. 4).

these oxide ceramics at their respective $\Delta T_{\mathrm{c}}$.

Figs. 3 and 4 show the transverse rupture strength $\sigma_{\mathrm{f}}$ results for the hot-pressed $\mathrm{Al}_{2} \mathrm{O}_{3}$ and NTK-HC2 respectively over the range of cross-head rates available in an Instron testing machine (i.e. $10^{-2}$ to $50 \mathrm{~cm} \mathrm{~min}^{-1}$ ). Apparently $\sigma_{\mathrm{f}}$ for both materials is independent of loading rates. Further experiments conducted at General Motors Technical Center using instrumented impact tests show that over the impact velocity range of 0.75 to $2.5 \mathrm{~m} \mathrm{sec}^{-1}$, the bend strengths of the oxide ceramics likewisely do not exhibit any loading rate dependence. In broadest terms, it may be said that $\sigma_{\mathrm{f}} \approx 75 \times 10^{3}$ psi for the hot-pressed $\mathrm{Al}_{2} \mathrm{O}_{3}$ and $\approx 100 \times 10^{3}$ psi for the composite ceramic NTK$\mathrm{HC} 2$ for these loading rates.

Three-point bend strengths of these two oxide ceramics within the temperature range of 25 to $800^{\circ} \mathrm{C}$ are shown in Figs. 5 and 6 . Within experimental scatter, it appears that $\sigma_{\mathrm{f}}$ is independent of the range of temperature under investigation.

\subsection{Fracture toughness results}

The fracture toughness $\left(K_{\mathrm{IC}}\right)$ results for the hotpressed $\mathrm{Al}_{2} \mathrm{O}_{3}$ and NTK-HC2 in the loading rate range of $10^{-2}$ to $50 \mathrm{~cm} \mathrm{~min}^{-1}$ are shown in Figs. 7 and 8 . These results are obtained from fracture experiments using surface indentation pre-cracked 


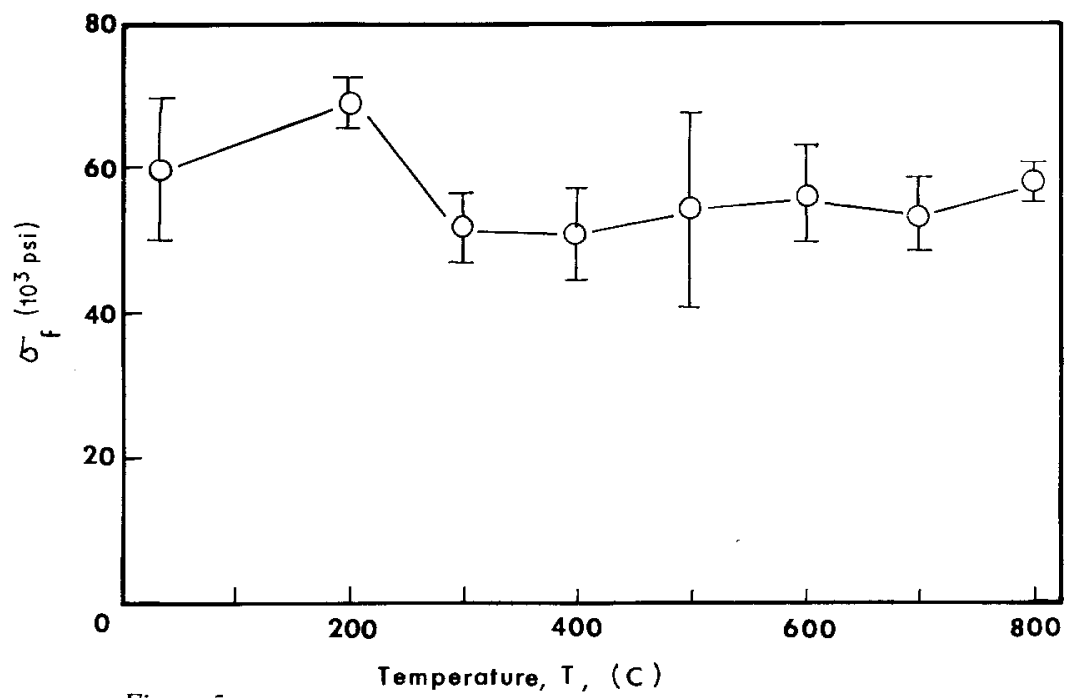

Figure 5 .

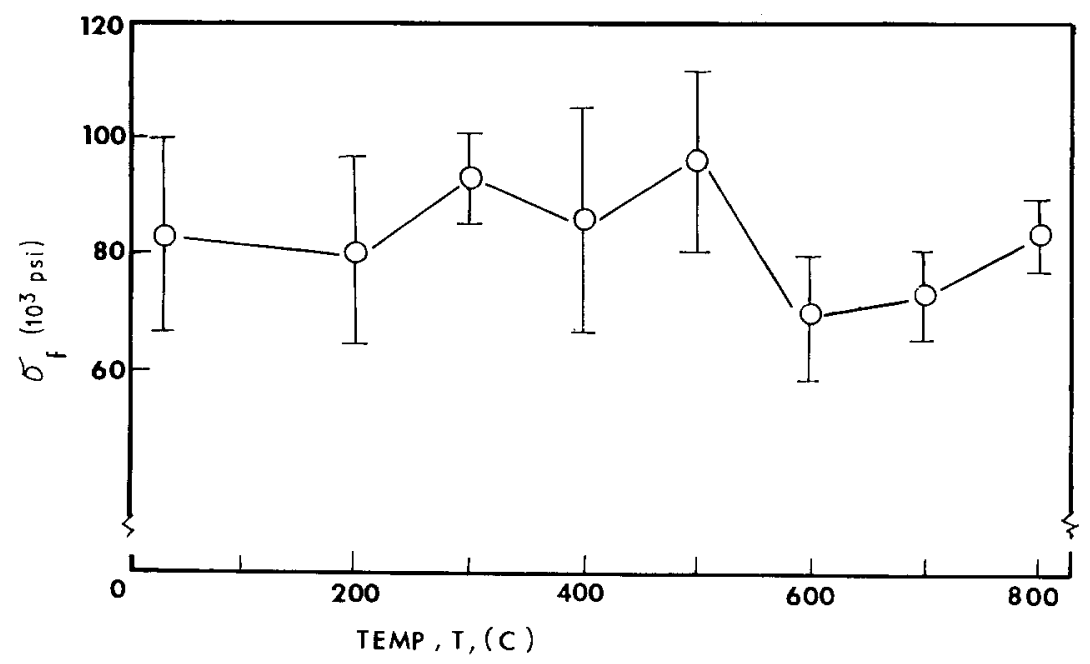

Figure 6.

Figures 5 and 6 Temperature dependence of bend strength for hot-pressed $\mathrm{Al}_{2} \mathrm{O}_{3}$ (Fig. 5) and NTK-HC2 (Fig. 6).

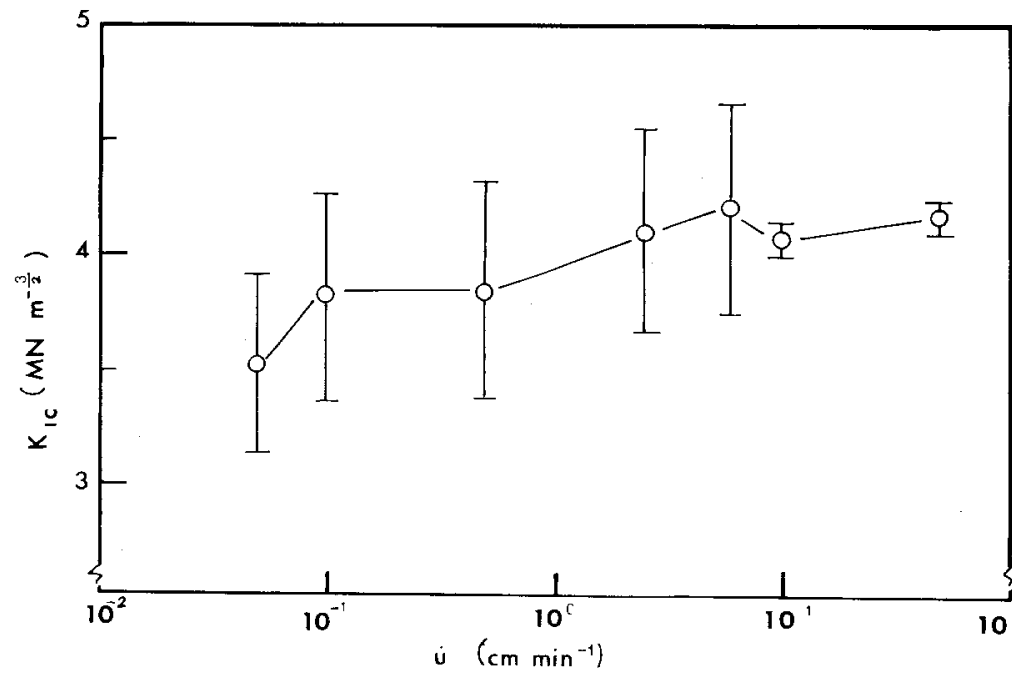

Figure 7 Variation of critical stress intensity factor $\left(K_{\mathbf{I C}}\right)$ with crosshead rate $(\dot{u})$ for hot-pressed alumina. 
Figure 8 Variation of critical stress intensity factor $\left(K_{\text {IC }}\right)$ with crosshead rate $(\dot{u})$ for NTK-HC2.
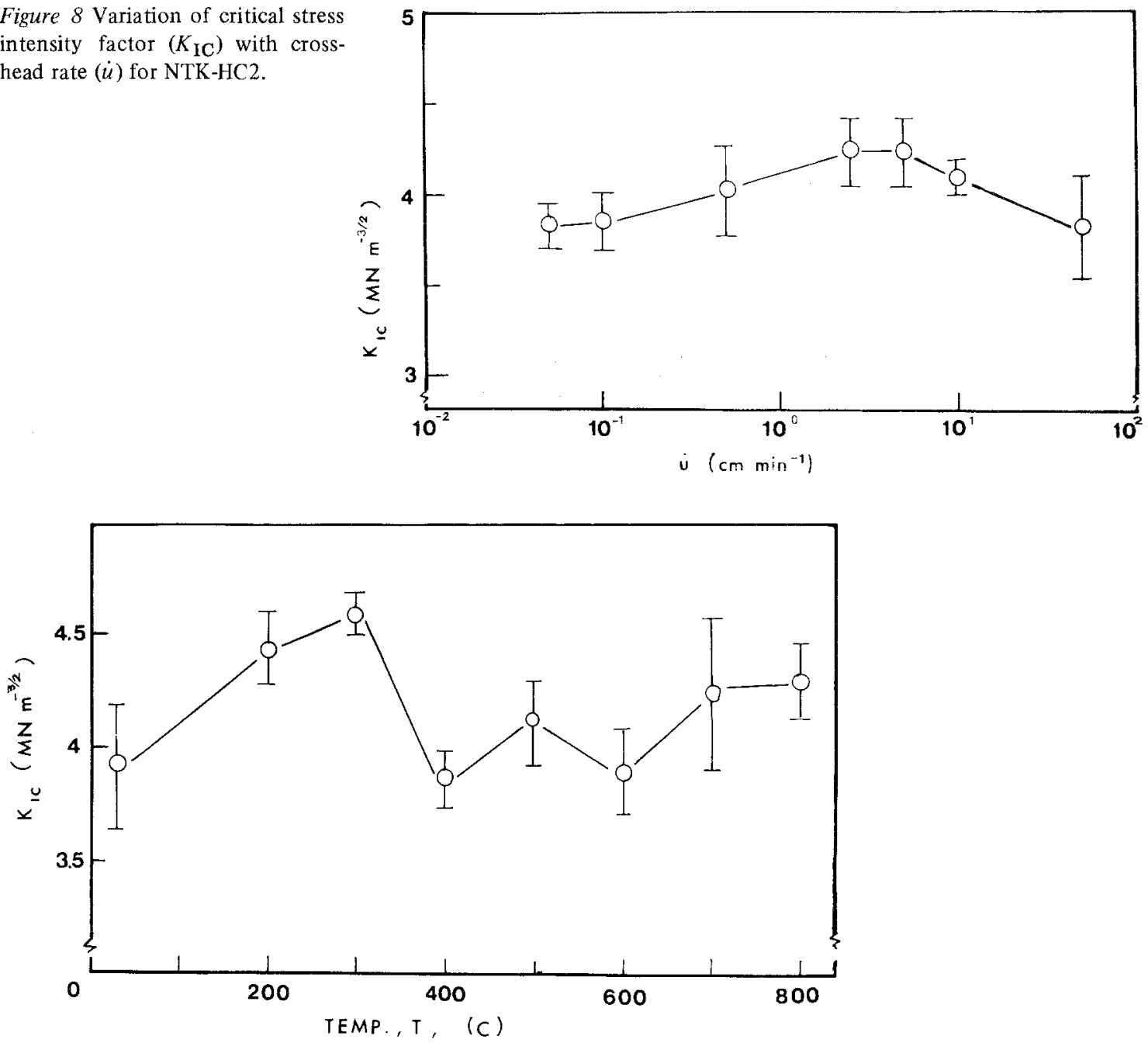

Figure 9.

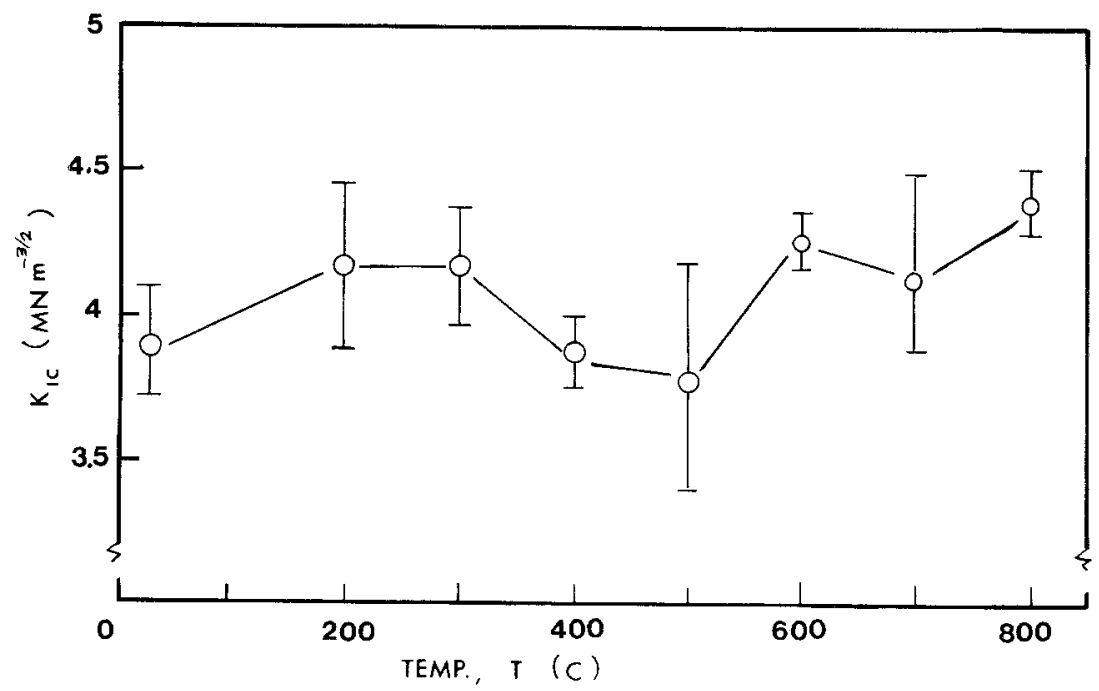

Figure 10

Figures 9 and 10 Temperature dependence of $K_{\mathrm{IC}}$ for hot-pressed alumina (Fig. 9) and NTK-HC2 (Fig. 10). 
testpieces. There is a scatter of about $\pm 12 \%$ of the mean value for the hot-pressed $\mathrm{Al}_{2} \mathrm{O}_{3}$ and $\pm 6 \%$ for the NTK-HC2 composite ceramic. Roughly speaking, both materials have an average $K_{\text {IC }}$ values of about $4 \mathrm{MN} \mathrm{m}^{-3 / 2}$ (or $4 \times 10^{3}$ psi in. $^{1 / 2}$ ) which is rather independent of the range of crosshead rates shown. (Note that for $10^{-2}<\dot{u}<10^{1}$ $\mathrm{cm} \mathrm{min}^{-1}$, NTK-HC2 and $\mathrm{Al}_{2} \mathrm{O}_{3}$ both appear to show a tendency of increasing $K_{\text {IC }}$ with cross-head rate).

Figs. 9 and 10 show the temperature dependence of $K_{\text {IC }}$ results for the oxide ceramics in the temperature range of 25 to $800^{\circ} \mathrm{C}$. Within experimental scatter, it may be concluded that $K_{\text {IC }}$ for both materials remains rather constant at $4 \mathrm{MN} \mathrm{m}^{-3 / 2}$. In a previous investigation [3], we have reported increases of $K_{\mathrm{IC}}$ at and above $800^{\circ} \mathrm{C}$ for two tool carbides* (i.e. titanium carbide and tungsten carbide). However, this toughness strengthening effect (at high temperatures) does not seem to exist for these two oxide ceramics. It may further be noted that since both $K_{\text {IC }}$ and $\sigma_{\mathrm{f}}$ are in the broadest terms independent of temperature and cross-head rate (i.e. within the range of the present investigation), the damage resistance parameters $\left(K_{\mathrm{IC}} / \sigma_{\mathrm{f}}\right)^{2}$ are, therefore, constant in magnitude. These are respectively $16 \sim 26 \times 10^{-4}$ and $30 \sim 60 \times 10^{-4}$ in. for the composite NTK-HC2 and hot-pressed pure $\mathrm{Al}_{2} \mathrm{O}_{3}$, respectively. The constancy of $\left(K_{\mathrm{IC}} / \sigma_{\mathrm{f}}\right)^{2}$ of these two oxide ceramics, being independent of both temperature and rate, should be contrasted with those carbide tools (which have a rate dependent $\left(K_{\mathrm{IC}} / \sigma_{\mathrm{f}}\right)^{2}$ parameter) and turbine ceramics (which exhibit a temperature dependent $\left(K_{\mathrm{IC}} / \sigma_{\mathrm{f}}\right)^{2}$ term) studied in previous investigations [1].

The specific fracture resistance $(R)$ of the oxide ceramics was also determined from the work of fracture method [8]. Briefly, the thermally shocked three-point bend specimens were broken and the total fracture work estimated from the areas under the load-deflection diagrams, and by measuring the fractured areas (this estimation was complicated by the fact that the shocked samples had many minute thermal-shock induced cracks) of the broken testpieces, $R$ could be easily calculated. Fig. 11 shows these $R$-results for the oxide ceramics. As expected, the specific fracture resistance is independent of the quenching temperature. In broadest terms, $R$ for the hot-pressed pure $\mathrm{Al}_{2} \mathrm{O}_{3}$ is about $80 \mathrm{~J} \mathrm{~m}^{-2}$ and that of NTK$\mathrm{HC} 2$ is roughly $100 \mathrm{~J} \mathrm{~m}^{-2}$. The room temperature $R$-values shown at the extreme left of the figure were not determined from the work of fracture method but rather were estimated from the corresponding $K_{\text {IC }}$ results (i.e. Figs. 7 and 8 ) through a conversion equation where $R=K_{\mathrm{IC}}^{2}\left(1-\nu^{2}\right) / E$. They are, in general, somewhat lower than the other $R$-values (i.e. 60 and $80 \mathrm{~J} \mathrm{~m}^{-2}$ as opposed to 80 and $100 \mathrm{~J} \mathrm{~m}^{-2}$, respectively, for $\mathrm{Al}_{2} \mathrm{O}_{3}$ and NTK-HC2.)
Figure II Specific work of fracture $(R)$ for the oxide ceramics as inferred from after-shock samples.

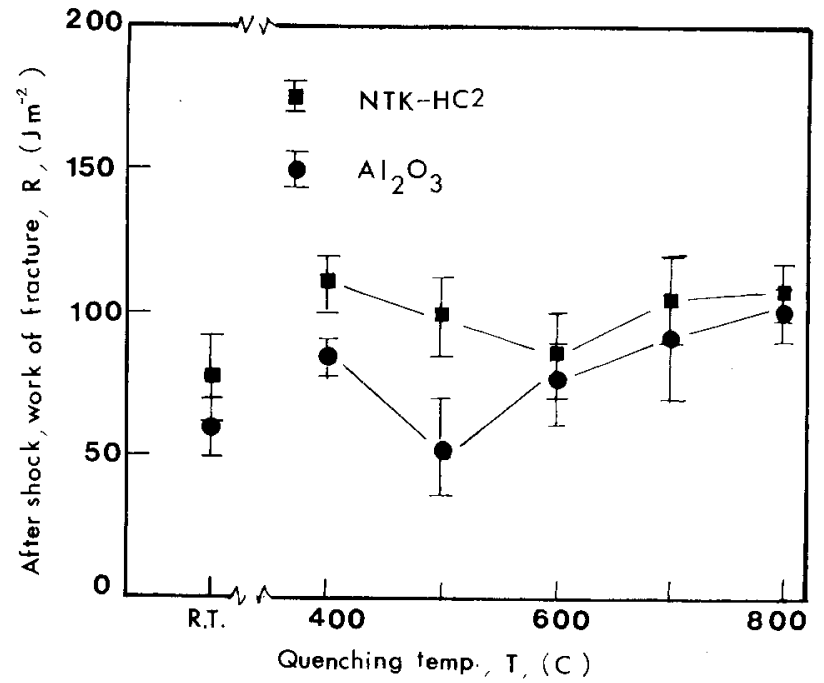

* This fact has been explained [3] in terms of the relaxation of tensile residual stresses around the crack tip region (as a consequence of the hardness indentation) which otherwise have aided in causing crack propagation. 
T A B LE II Thermal shock resistance evaluation of oxide ceramics

\begin{tabular}{|c|c|c|c|c|c|c|c|c|c|}
\hline \multirow[t]{2}{*}{ Material } & \multicolumn{7}{|c|}{ Thermal cycles completed before failure } & \multirow{2}{*}{$\begin{array}{l}\left(k \sigma_{\mathrm{f}} / E \alpha\right) \\
\left(\mathrm{cal} \mathrm{sec} \mathrm{se}^{-1} \mathrm{~cm}^{-1}\right)\end{array}$} & \multirow{2}{*}{$\begin{array}{l}\left(K_{\mathrm{IC}} / \sigma_{\mathrm{f}}\right)^{2} \\
\text { (in.) }\end{array}$} \\
\hline & $250^{\circ} \mathrm{C}$ & $300^{\circ} \mathrm{C}$ & $400^{\circ} \mathrm{C}$ & $500^{\circ} \mathrm{C}$ & $600^{\circ} \mathrm{C}$ & $700^{\circ} \mathrm{C}$ & $800^{\circ} \mathrm{C}$ & & \\
\hline Hot-pressed $\mathrm{Al}_{2} \mathrm{O}_{3}$ & $10(1)^{*}$ & 10 & 10 & 10 & 10 & 10 & 10 & 11.73 & $30 \times 10^{-4}$ \\
\hline $\begin{array}{l}\text { Composite ceramic } \\
\text { NTK-HC } 2\end{array}$ & $10(2) *$ & 10 & 10 & 10 & 10 & 6 & & 14.07 & $16 \times 10^{-4}$ \\
\hline
\end{tabular}

* Number in parentheses indicates cycles for initiation of surface cracks.

\subsection{Relation between strength loss and damage resistance parameter}

The fraction retained strength of a rectangular beam, after the critical thermal shock, is approximately given by $[1,3]$

$$
\frac{\sigma_{\mathrm{a}}}{\sigma_{\mathrm{f}}}=\left[0.32 \pi\left(1-v^{2}\right) N / V\right]^{1 / 4}\left[K_{\mathrm{IC}} / \sigma_{\mathrm{f}}\right]^{3 / 2},
$$

where $N / V$ is the number of cracks per unit volume of the stressed specimen.* Hence, using appropriate $\left(K_{\mathrm{IC}} / \sigma_{\mathrm{f}}\right)^{2}$ values at their respective critical quenching temperatures for the two oxide ceramics, and with $N / V$ approximately equal to $6.4 \times 10^{3}$ cracks in..$^{-3}$ (for the hot-pressed $\mathrm{Al}_{2} \mathrm{O}_{3}$ ) and $12 \times 10^{3}$ cracks in. $^{-3}$ (for the composite ceramic NTK-HC2), the fractional strengths retained are 0.13 and 0.084 for the hot-pressed $\mathrm{Al}_{2} \mathrm{O}_{3}$ and NTK-HC2 ceramic respectively. These results agree fairly well with the corresponding observed values of 0.200 and 0.170 .

It is apparent from Figs. 1 and 2 that the retained strength $\left(\sigma_{\mathrm{a}}\right)$ for a given shock temperature depends somewhat on the number of shocks. This decreases slightly with increasing thermal shock cycles, which possibly indicates a further degradation effect (i.e. further enlargement of sub-critical cracks) due to thermal fatigue in these two oxide ceramics

\subsection{Comparison of thermal-stress resistance} The thermal shock resistance of these two oxide ceramics may be compared using one of the following three methods: (1) traditional thermal shock stress evaluation [1, 3], (2) critical quenching temperature $\left(T_{\mathrm{c}}\right)$ at which thermal cracks initiate and (3) the percentage strength retained after shocking through $\Delta T_{\mathrm{c}}$.

The first method has been described in detail in [1]. Briefly, three-point bend specimens (or rectangular tool inserts) were subjected to thermal cycles with increasing shock severity intervals. The number of cycles to cause surface cracks and final failure of specimens were recorded. Table II shows the experimental results for these two ceramics. Apparently, these results can be correlated with the parameters $\left(k \sigma_{\mathrm{f}} / E \alpha\right)$ and $\left(K_{\mathrm{IC}} / \sigma_{\mathrm{f}}\right)^{2}$ for crack initiation and final fracture respectively. Based on crack initiation, since both materials have more or less the same $\left(k \sigma_{\mathrm{f}} / E \alpha\right)$ values, it is difficult to say which is better. The experimental results suggest that after the first thermal cycle at $250^{\circ} \mathrm{C}$, many cracks have been developed in the hot-pressed $\mathrm{Al}_{2} \mathrm{O}_{3}$. This only happens with NTK-HC2 after the second thermal cycle. Based on resistance to crack propagation until final failure, the results show that the hot-pressed pure $\mathrm{Al}_{2} \mathrm{O}_{3}$ is better than NTK-HC2. This observation is in agreement with the larger $\left(K_{\mathrm{IC}} / \sigma_{\mathrm{f}}\right)^{2}$ value for the pure $\mathrm{Al}_{2} \mathrm{O}_{3}$. It is rather difficult to assess the relative merits (to crack initiation) of these two materials using methods 2 and 3 since they both have approximately the same critical quenching temperature $\left(T_{\mathrm{c}} \approx 200^{\circ} \mathrm{C}\right)$ and retained bend strength ( 18 to $20 \times 10^{3}$ psi).

\section{Conclusions}

The damage resistance parameter $\left(K_{\mathrm{IC}} / \sigma_{\mathrm{f}}\right)^{2}$ for both the hot-pressed alumina and the composite ceramic (NTK-HC2) has been determined and found to be independent of loading rates $(0.05$ $\mathrm{cm} \mathrm{min}^{-1}$ to $2.5 \mathrm{~m} \mathrm{sec}^{-1}$ ) and temperature ( 25 to $800^{\circ} \mathrm{C}$ ). The fracture strength behaviour after severe thermal shocks may be explained in terms of Hasselman's model, so that the instantaneous strength loss at their respective critical quenching temperature may be calculated using these $\left(K_{\mathrm{IC}} / \sigma_{\mathrm{f}}\right)^{2}$ values.

Within experimental error, both oxide ceramics have roughly the same critical quenching temperature and retained strength so that their resistance to crack initiation is roughly the same. However, the hot-pressed pure $\mathrm{Al}_{2} \mathrm{O}_{3}$ is found to have slightly better resistance to crack propagation than the composite ceramic NTK-HC2 (because of its

* Since $N / V$ is not directly measurable, it is estimated from the surface crack density $\left(N_{\mathrm{s}}\right)$, where $N / V \bumpeq N_{\mathrm{s}}^{3 / 2}$. 
bigger $\left(K_{\mathrm{IC}} / \sigma_{\mathrm{f}}\right)^{2}$ value). In this respect, it appears that the pure oxide ceramic is better in cutting services where thermal shock effects are significant.

\section{Acknowledgements}

This work was carried out under a research grant from General Motors Corporation. I am happy to acknowledge the guidance and useful discussion with Dr Jamie Hsu of G.M. Technical Center during the various stages of this investigation. The specimens are specially prepared by the manufacturers concerned, their results reported here are therefore not necessarily typical of commercial products.

\section{References}

1. Y. W. MAI and A. G. ATKINS, J. Mater. Sci. 10 (1975) 1904.

2. Idem, J. Amer. Ceram. Soc. Bull. 54 (1973) 593.

3. Y. W. MAI, Final Technical Report to General Motors Corp., September 1975.

4. D. P. H. HASSElMAN, J. Amer. Ceram. Soc. 52 (1969) 600 .

5. S. S. MANSON, NCAA Technical Note 2393 , July (1953).

6. R. W. DAVIDGE and G. TAPPIN, Trans. Brit. Ceram. Soc. 66 (1967) 405.

7. R. A. SACK, Proc. Phys. Soc. (London) A58 (1946) 729.

8. H. G. TATTERSALL and G. TAPPIN, J. Mater. Sci. 1 (1966) 296.

Received 14 January and accepted 8 February 1976. 